\title{
Evaluation of cardiovascular biomarkers in patients with age-related wet macular degeneration
}

\author{
This article was published in the following Dove Press journal: \\ Clinical Ophthalmology \\ 25 August 2014 \\ Number of times this article has been viewed
}

\author{
Sadullah Keles' \\ Orhan Ates' \\ Baki Kartal ${ }^{2}$ \\ Hamit Hakan Alp ${ }^{3}$ \\ Metin Ekinci ${ }^{4}$ \\ Erdinc Ceylan ${ }^{2}$ \\ Osman Ondas ${ }^{5}$ \\ Eren Arpali ${ }^{2}$ \\ Semih Dogan ${ }^{6}$ \\ Kenan Yildirim ${ }^{7}$ \\ Mevlut Sait Keles ${ }^{8}$ \\ 'Department of Ophthalmology, \\ School of Medicine, Ataturk \\ University, Erzurum, Turkey; \\ 2Department of Ophthalmology, \\ Regional Training and Research \\ Hospital, Erzurum, Turkey; \\ ${ }^{3}$ Department of Biochemistry, School \\ of Medicine, Yuzuncu Yil University, \\ Van, Turkey; ${ }^{4}$ Department of \\ Ophthalmology, School of Medicine, \\ Kafkas University, Kars, Turkey; \\ ${ }^{5}$ Department of Ophthalmology, Erbaa \\ Government Hospital, Tokat, Turkey; \\ ${ }^{6}$ Department of Ophthalmology, \\ Kolan Hospital, Istanbul, Turkey; \\ ${ }^{7}$ Department of Ophthalmology, Igdır \\ Government Hospital, Igdır, Turkey; \\ ${ }^{8}$ Department of Biochemistry, School \\ of Medicine, Ataturk University, \\ Erzurum, Turkey
}

Correspondence: Sadullah Keles

Ophthalmology Department, Faculty

of Medicine, Ataturk University,

25240, Erzurum, Turkey

$\mathrm{Tel}+904422317983$

$\mathrm{Fax}+90442236$ I3 01

Email opdr_sadullah@yahoo.com
Aim: To evaluate levels of homocysteine, asymmetric dimethylarginine (ADMA), and nitric oxide (NO), as well as activity of endothelial NO synthase (eNOS), in patients with age-related macular degeneration (AMD).

Methods: The levels of homocysteine, ADMA, and NO and activity of eNOS in patients who were diagnosed with wet AMD by fundus fluorescein angiography $(n=30)$ were compared to a control group with no retinal pathology $(\mathrm{n}=30)$.

Results: Levels of homocysteine and ADMA were found to be significantly higher in the wet AMD group than in the control group $(P<0.001)$, whereas NO levels and eNOS activity were higher in the control group $(P<0.001)$. In the wet AMD group, we detected a 2.64- and 0.33fold increase in the levels of ADMA and homocysteine, respectively, and a 0.49- and 2.41-fold decrease in the eNOS activity and NO level, respectively.

Conclusion: Elevated levels of homocysteine and ADMA were observed in patients with wet AMD. Increased ADMA may be responsible for the diminished eNOS activity found in these patients, which in turn contributes to the decrease in NO levels, which likely plays a role in the pathogenesis of AMD.

Keywords: age-related macular degeneration, homocysteine, asymmetric dimethylarginine, nitric oxide, endothelial nitric oxide synthase activity

\section{Introduction}

Age-related macular degeneration (AMD) is a major cause of vision impairment and blindness in populations over 65 years of age in developed countries. The disease is categorized in two types: neovascular and non-neovascular. ${ }^{1}$ Genetic predisposition, age, hypertension, smoking, and hypercholesterolemia are known risk factors. ${ }^{1,2}$ Despite the identification of several risk factors, the etiopathogenesis of AMD is not fully understood. ${ }^{3-5}$ As the condition presents in older patients, age-related metabolic and physiologic factors may be involved in AMD pathogenesis.

In studies evaluating the role of homocysteine in vascular function and disease, high levels of homocysteine have been found to be an independent risk factor for atherosclerosis, cardiovascular diseases, and venous thrombosis. ${ }^{6-8}$ Nitric oxide (NO) has been found to play a role in the formation of vasculature, regulation of vascular tone, and cell-to-cell interactions within blood vessels. ${ }^{9}$ Increases in asymmetric dimethylarginine (ADMA) have been shown to be related to hypertension, atherogenesis, obesity, and diabetes. $^{10-13}$

Of these mediators, homocysteine is formed as an intermediate product in methionine metabolism and is the precursor for S-adenosyl methionine, a substrate responsible for methylation in metabolic reactions. ${ }^{14} \mathrm{NO}$ is synthesized from arginine by NO synthase (NOS) in vascular endothelium and functions as one of the main vasoactive 
mediators. ${ }^{9} 15$ ADMA, however, is the primary inhibitor of endothelial NOS (eNOS). ${ }^{16}$

The aim of this study was to compare levels of homocysteine, ADMA, NO, and eNOS activity between patients with wet AMD and a control group consisting of healthy volunteer subjects, and to use the findings to evaluate the possible relationship of these parameters to the pathophysiology of wet AMD.

\section{Materials and methods}

Thirty wet AMD patients and 30 healthy volunteers were enrolled in this study. The groups were matched for age, sex, and detailed medical history (hypertension, diabetes, coronary heart disease, cerebrovascular disease, medication use, and smoking). Patients and volunteers with coronary heart disease, cerebrovascular disease, liver and kidney dysfunction, vitamin deficiencies, retinal vascular disease, or anterior optic neuropathy were excluded from the study due to the possibility of false positive results in serum homocysteine level analysis.

Ophthalmological examination of the patients in both study groups was carried out (visual acuity, slit biomicroscopy, intraocular pressure, dilated fundoscopy, optical coherence tomography [OCT], and fundus photography). Fundus fluorescein angiography was performed on patients who showed pigment epithelial detachment or subretinal fluid in OCT. Patients in whom fundus fluorescein angiography revealed choroidal neovascularization in the macular area in one or both eyes were included in the study. The control group subjects had visual acuity of 10/10 in both eyes. Subjects were accepted to the control group when minimal retinal pigment epithelial changes were found in fundoscopic examination, under the conditions that drusen were not present and that OCT did not show pigment epithelial detachment or subretinal fluid.

All patients provided informed consent for participation in the study and all procedures involved. The study was planned according to the ethics guidelines of the Declaration of Helsinki, and the study protocol was approved by the local ethics committee of Ataturk University's Faculty of Medicine (Erzurum, Turkey). Peripheral venous blood samples were collected and stored at $-80^{\circ} \mathrm{C}$. The samples were centrifuged at $4^{\circ} \mathrm{C}$.

\section{Biochemical analysis}

A Chromsystems Instruments \& Chemicals GmbH (Gräfelfing, Germany) kit was used for total homocysteine level analysis. Plasma samples $(100 \mu \mathrm{L})$ underwent precipitation and derivatization. Homocysteine levels were determined using high-performance liquid chromatography with fluorescent detection. The excitation and emission wavelengths of the fluorescent detector were set to $385 \mathrm{~nm}$ and $515 \mathrm{~nm}$, respectively. The kit's limit of detection was $1 \mu \mathrm{mol} / \mathrm{L}$ and limit of linearity was $400 \mu \mathrm{mol} / \mathrm{L}$. Results were given in $\mu \mathrm{mol} / \mathrm{L}$.

eNOS activity was measured by enzyme-linked immunosorbent assay using a commercially available kit (Quantakine $^{\circledR}$; R\&D Systems, Inc., Minneapolis, MN, USA). After plasma samples were processed, color development was quantified by measuring absorbance at $450 \mathrm{~nm}$ and eNOS activity was calculated. Results were given in IU/L.

Plasma NO levels (nitrite + nitrate) were measured using Griess reagent, as previously described.${ }^{17}$ Briefly, nitrate was converted to nitrite using nitrate reductase; Griess reagent containing sulfanilamide and $\mathrm{N}$-(1-naphthyl) was added. After the reaction of nitrite and Griess reagent, a deep purple azo compound formed, which can be quantified at $540 \mathrm{~nm}$ (using sodium citrate as a standard). Azo compound concentration was expressed in $\mu \mathrm{mol} / \mathrm{L}$.

ADMA was measured fluorometrically using the Agilent 1100 Series HPLC System (Agilent Technologies, Santa Clara, CA, USA) and a commercially available kit (EUREKA srl, Chiaravalle, Italy). The Agilent system consists of an isocratic pump, column frame, autosampler, and fluorescence detector. Flow rate was $1 \mathrm{~mL} / \mathrm{min}$; excitation and emission wavelengths of the fluorescence detector were 420 and 483 , respectively. ADMA concentration was expressed as $\mu \mathrm{mol} / \mathrm{L}$.

\section{Statistical analysis}

Data were analyzed using SPSS statistics software (v 17.0; SPSS Inc., Chicago, IL, USA). Data normality was verified by the Kolmogorov-Smirnov test. Independent sample $t$-test and Mann-Whitney $U$-tests were used to analyze the differences between two independent groups; Pearson's test was used for correlation analysis, and chi-square test was used for qualitative comparisons. Results were accepted as statistically significant at $P<0.05$.

\section{Results}

Seventeen male (56.7\%) and 13 female (43.3\%) AMD patients, and 16 male (53.3\%) and 14 female (46.7\%) control subjects, were included in this study. The average ages were $64.53 \pm 1.65$ (range 62-68) years and 63.83 \pm 2.53 (range 60-69) years for AMD patients and healthy controls, respectively. There were no statistically significant differences between AMD patients and controls in terms of age $(t=1.267$, 


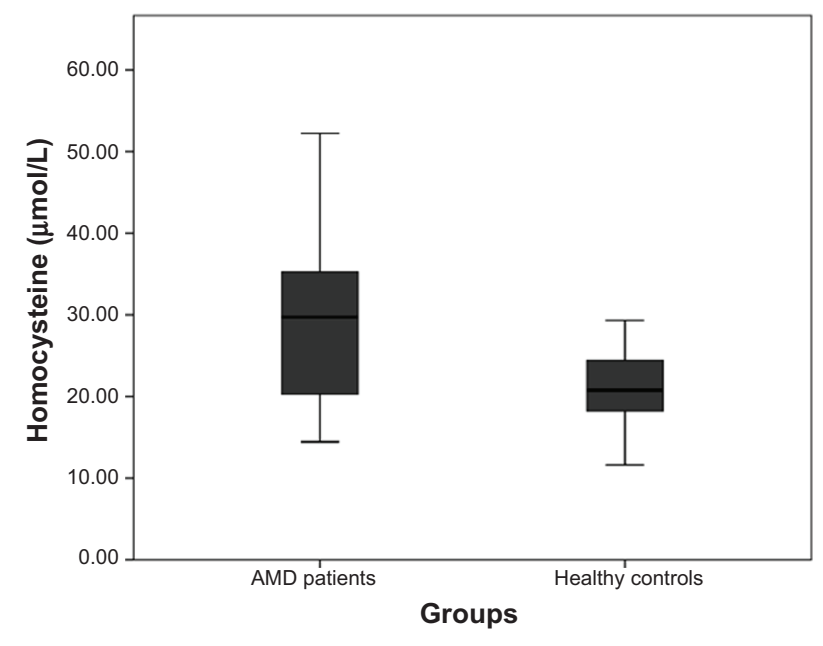

Figure I Homocysteine level averages and distributions for both groups. Abbreviation: AMD, age-related macular degeneration.

$P=0.210)$ or sex distribution $\left(\chi^{2}=0.067, P=0.795\right)$. There was a significant difference in visual acuity between AMD and control groups $(Z=-6,744, P<0.001)$. The average visual acuity scores were $0.99 \operatorname{logMAR} \pm 0.4$ (standard deviation [SD]) and $0.07 \log$ MAR \pm 0.08 (SD) for AMD group and controls, respectively.

Levels of homocysteine and ADMA were found to be significantly higher in the wet AMD group than in the control group $(P<0.001)$ (Figures 1 and 2$)$, whereas NO levels and eNOS activity were higher in the control group $(P<0.001)$. In the wet AMD group, we detected a 2.64- and 0.33 -fold increase in the levels of ADMA and homocysteine, respectively, and a 0.49 - and 2.41-fold decrease in the eNOS activity and NO level, respectively. Biochemical findings are summarized in Table 1.

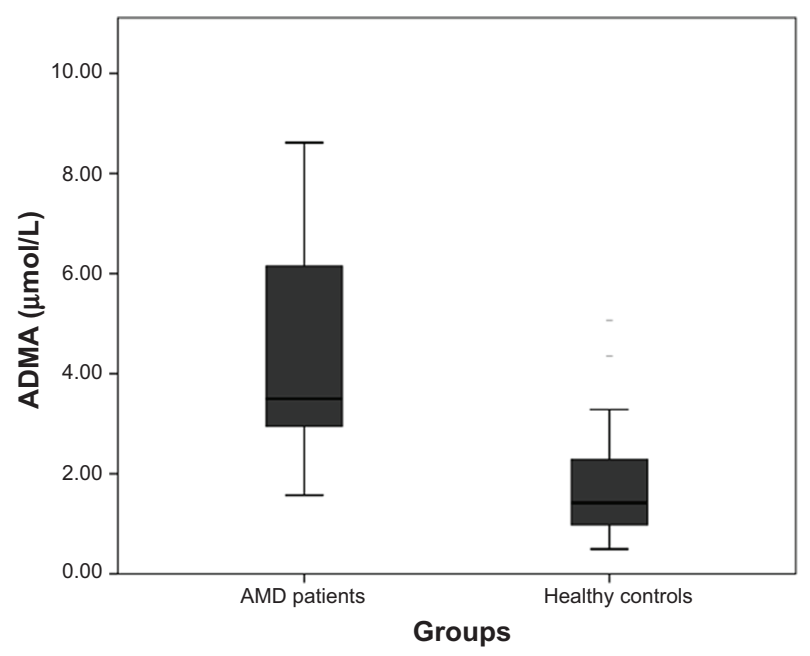

Figure 2 ADMA level averages and distributions in the two groups. Abbreviations: ADMA, asymmetric dimethylarginine; AMD, age-related macular degeneration.
Statistically significant negative correlations were found between ADMA and eNOS ( $r=-0.484, P<0.01)$ (Figure 3$)$. There was a positive correlation between NO levels and eNOS activity $(r=0.438, P<0.01)$ (Figure 4$)$.

\section{Discussion}

Several studies have indicated a possible link between coronary heart disease, which is the most common disease in elderly patients, and AMD, which affects the same age group. ${ }^{18-21}$ Although a causal relationship between atherosclerosis and AMD has not been fully established, atherosclerosis has been implicated as a potential risk factor. ${ }^{22,23}$ Therefore, it is logical to hypothesize that mediators of atherosclerosis may be involved in AMD pathogenesis. Based on this hypothesis, the current study aimed to assess several biochemical parameters in AMD patients: homocysteine levels, an independent risk factor for cardiovascular disease; NO levels, a mediator for vascular relaxation; activity of eNOS, an enzyme that synthesizes NO; and levels of ADMA, an eNOS inhibitor.

Homocysteine has been shown to be an independent risk factor for cardiovascular diseases and has been especially associated with coronary heart disease. ${ }^{24-30}$ Hypercholesterolemia and homocysteine may promote the production of hydroxyl radicals, superoxide anions, and hydrogen peroxide by many cells. These radicals may act on various molecules and result in damage, such as initiating lipid peroxidation and contributing to cardiovascular disease. ${ }^{31}$ However, there are very few studies that have assessed homocysteine levels in AMD. In this study, we found significantly elevated levels of homocysteine in the AMD group compared to controls $(P<0.01)$. Our findings are in line with previous studies, which also showed increased homocysteine levels in AMD patients. ${ }^{32-34}$ Although the reason for increased homocysteine is not clear, several studies suggest that it is age related. ${ }^{35,36}$ Higher levels of serum homocysteine may be attributable to excesses of the homocysteine precursor methionine resulting from the degradation of protein-rich muscle tissue in older patients. ${ }^{37}$

NO is synthesized by vascular endothelium and functions as one of the main vasoactive mediators. NO plays many different roles in the regulation of the cardiovascular system, including vasodilatation in vascular tone, formation of vasculature, and cell-to-cell interactions within blood vessels. ${ }^{9} \mathrm{NO}$ is synthesized from L-arginine by NOS. There are three types of NOS in humans: eNOS, inducible NOS (iNOS), and neuronal NOS. ${ }^{38-40} \mathrm{NO}$ has as many regulative functions in the ocular system as it has in systemic blood flow. ${ }^{41,42}$ There is evidence supporting the protective role of 
Table I The results of assessed biochemical parameters

\begin{tabular}{|c|c|c|c|}
\hline Biochemical parameters & $\begin{array}{l}\text { AMD patients } \\
n=30\end{array}$ & $\begin{array}{l}\text { Healthy controls } \\
n=30\end{array}$ & Statistical results \\
\hline Homocysteine $(\mu \mathrm{mol} / \mathrm{L})$ & $29.1 I \pm 8.63(\mid 4.45-52.23)$ & $21.5 I \pm 4.5(I I .62-29.32)$ & $t=4.272, P<0.00 I^{a}$ \\
\hline ADMA $(\mu \mathrm{mol} / \mathrm{L})$ & $4.49 \pm 2.12(1.57-8.62)$ & 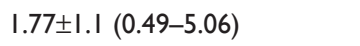 & $Z=-5.323, P<0.00 I^{b}$ \\
\hline $\mathrm{NO}(\mu \mathrm{mol} / \mathrm{L})$ & $36.24 \pm 12.85(48.25-193.70)$ & $111.94 \pm 35.94$ (17.7I-65.33) & $t=|0.86|, P<\left.0.00\right|^{a}$ \\
\hline eNOS (IU/L) & $109.44 \pm 86.38(43.16-377.35)$ & $224.75 \pm 40.9 \mid(|36.43-30| .64)$ & $Z=-5.249, P<0.00 I^{b}$ \\
\hline
\end{tabular}

Notes: andependent sample $t$-test. 'Mann-Whitney U-test.

Abbreviations: ADMA, asymmetric dimethylarginine; AMD, age-related macular degeneration; eNOS, endothelial nitric oxide synthase; NO, nitric oxide.

NO against increase in vascular resistance. ${ }^{43}$ Previous studies have shown that homocysteine exerts its adverse effect on endothelial function by increasing oxidative stress and decreasing the activity of NOS. ${ }^{44,45}$ In the current study, it was found that AMD patients had lower NO levels compared to controls $(P<0.01)$, which is consistent with a study by Totan et $\mathrm{al}^{46}$ wherein a decrease in NO levels in AMD patients compared to controls was also reported. However, Evereklioglu et al found elevated levels of NO in AMD patients. ${ }^{47}$ Elevated levels of NO may be related to increased iNOS expression. Increased iNOS expression in the endothelium can significantly increase endothelial NO. ${ }^{48}$ The authors considered NO to be a free radical and concluded that the increase in NO levels resulted in greater oxidative damage in AMD patients. ${ }^{48}$ Similarly, several studies showed that NO also reacts with oxygen and superoxide anion to form nitrogen dioxide and peroxynitrite anion, which are known cytotoxic oxygen radicals. ${ }^{49}$ Increased peroxynitrite concentration causes endothelial dysfunction. ${ }^{50}$ In another study examining $\mathrm{NO}$ in AMD, the NO levels were found to be lower in AMD patients than in controls, but the underlying

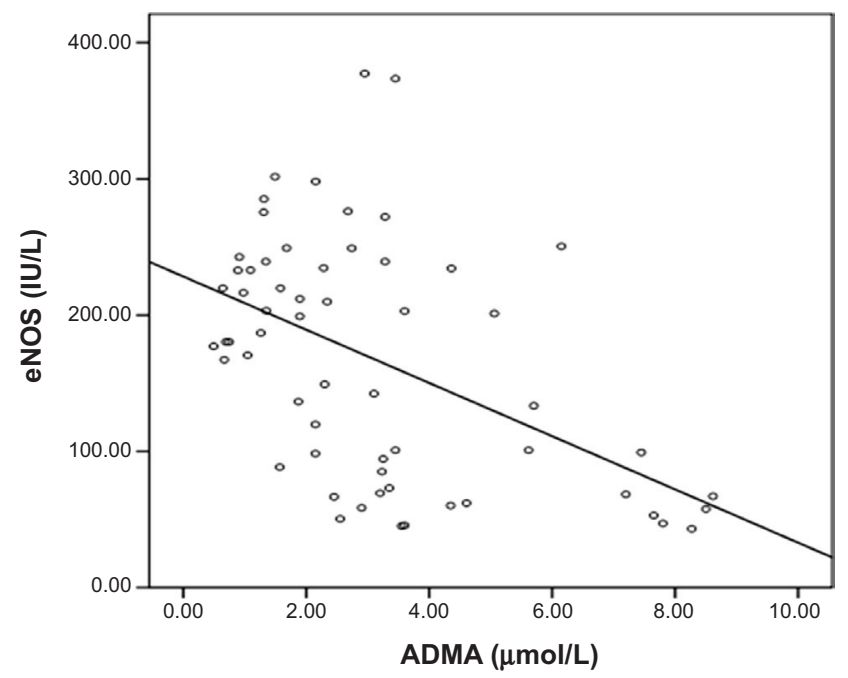

Figure 3 The negative correlation between ADMA and eNOS.

Abbreviations: ADMA, asymmetric dimethylarginine; eNOS, endothelial nitric oxide synthase. mechanism was not described. Friedman proposed that the decrease in NO levels may be a contributing factor in ocular system damage as well as play a role in AMD pathogenesis. $^{51}$

ADMA is one of the two known inhibitors of eNOS. The circulating level of the other inhibitor, NG-monomethyl-Larginine, is ten times less than that of ADMA; therefore, ADMA is considered the primary inhibitor of eNOS in humans. ${ }^{16}$ ADMA is excreted by the kidneys, and elevated ADMA has been found in patients with renal dysfunction. ${ }^{52}$ In our study, ADMA levels were significantly higher and eNOS activity was significantly lower in AMD patients than in controls $(P<0.01)$. The increased ADMA and diminished eNOS activity both contributed to the decreased levels of NO observed in AMD patients, as increased ADMA inhibits eNOS, resulting in decreased NO synthesis.

\section{Conclusion}

Advancing age is accompanied by increases in ADMA, a mediator in vasoactive processes. ADMA is responsible for inhibition of eNOS activity, which in turn causes low NO levels. Considering the importance of $\mathrm{NO}$ as a vasoactive

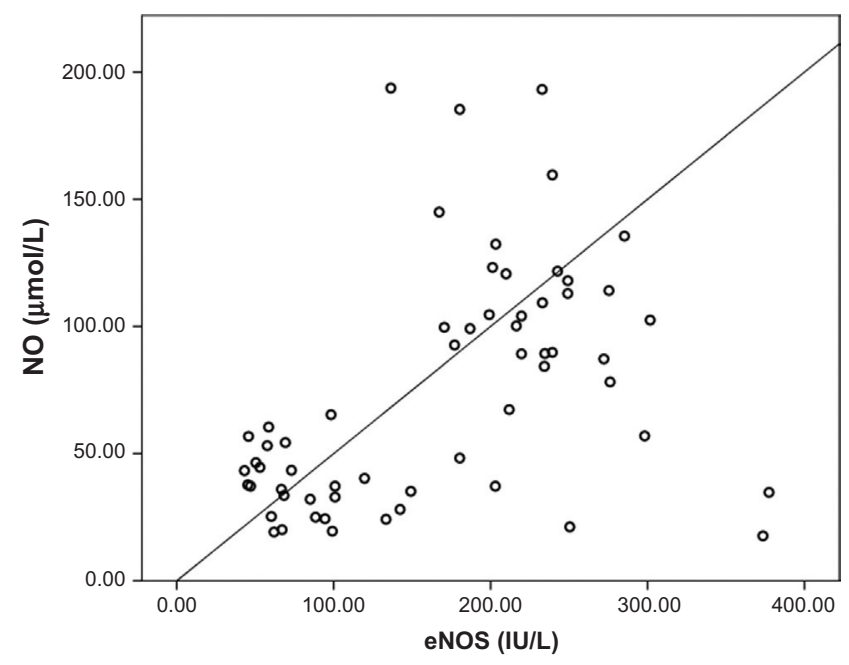

Figure 4 The positive correlation between eNOS activity and NO levels. Abbreviations: eNOS, endothelial nitric oxide synthase; NO, nitric oxide. 
agent, this decrease in NO levels may play a role in the pathogenesis of AMD.

\section{Disclosure}

The authors report no conflicts of interest in this work.

\section{References}

1. Lim LS, Mitchell P, Seddon JM, Holz FG, Wong TY. Age-related macular degeneration. Lancet. 2012;379(9827):1728-1738.

2. Archer DB, Gardiner TA. Electron microscopic features of experimental choroidal neovascularization. Am J Ophthalmol. 1981;91(4): 433-457.

3. Feigl B. Age-related maculopathy - linking aetiology and pathophysiological changes to the ischaemia hypothesis. Prog Retin Eye Res. 2009; 28(1):63-86.

4. Lotery A, Trump D. Progress in defining the molecular biology of age related macular degeneration. Hum Genet. 2007;122(3-4):219-236.

5. Solberg Y, Rosner M, Belkin M. The association between cigarette smoking and ocular diseases. Surv Ophthalmol. 1998;42(6):535-547.

6. Humphrey LL, Fu R, Rogers K, Freeman M, Helfand M. Homocysteine level and coronary heart disease incidence: a systematic review and meta-analysis. Mayo Clin Proc. 2008;83(11):1203-1212.

7. Nygård $\mathrm{O}$, Vollset SE, Refsum H, et al. Total plasma homocysteine and cardiovascular risk profile. The Hordaland Homocysteine Study. JAMA. 1995;274(19):1526-1533.

8. Rees MM, Rodgers GM. Homocysteinemia: association of a metabolic disorder with vascular disease and thrombosis. Thromb Res. 1993;71(5): 337-359.

9. Davis KL, Martin E, Turko IV, Murad F. Novel effects of nitric oxide. Annu Rev Pharmacol Toxicol. 2001;41:203-236.

10. Holm T, Aukrust P, Aagaard E, et al. Hypertension in relation to nitric oxide, asymmetric dimethylarginine, and inflammation: different patterns in heart transplant recipients and individuals with essential hypertension. Transplantation. 2002;74(10):1395-1400.

11. McLaughlin T, Stühlinger M, Lamendola C, et al. Plasma asymmetric dimethylarginine concentrations are elevated in obese insulin-resistant women and fall with weight loss. J Clin Endocrinol Metab. 2006;91(5) 1896-1900.

12. Ito A, Tsao PS, Adimoolam S, Kimoto M, Ogawa T, Cooke JP. Novel mechanism for endothelial dysfunction: dysregulation of dimethylarginine dimethylaminohydrolase. Circulation. 1999;99(24):3092-3095.

13. Krzyzanowska K, Mittermayer F, Krugluger W, et al. Asymmetric dimethylarginine is associated with macrovascular disease and total homocysteine in patients with type 2 diabetes. Atherosclerosis. 2006; 189(1):236-240.

14. Chiang PK, Gordon RK, Tal J, et al. S-Adenosylmethionine and methylation. FASEB J. 1996;10(4):471-480.

15. Palmer RM, Ashton DS, Moncada S. Vascular endothelial cells synthesize nitric oxide from L-arginine. Nature. 1988;333(6174):664-666.

16. Chan NN, Chan JC. Asymmetric dimethylarginine (ADMA): a potential link between endothelial dysfunction and cardiovascular diseases in insulin resistance syndrome? Diabetologia. 2002;45(12):1609-1616.

17. Moshage H, Kok B, Huizenga JR, Jansen PL. Nitrite and nitrate determinations in plasma: a critical evaluation. Clin Chem. 1995;41(6 Pt 1): 892-896.

18. Tan JS, Mitchell P, Smith W, Wang JJ. Cardiovascular risk factors and the long-term incidence of age-related macular degeneration: the Blue Mountains Eye Study. Ophthalmology. 2007;114(6):1143-1150.

19. Duan Y, Mo J, Klein R, et al. Age-related macular degeneration is associated with incident myocardial infarction among elderly Americans. Ophthalmology. 2007;114(4):732-737.

20. Chaine G, Hullo A, Sahel J, et al. Case-control study of the risk factors for age related macular degeneration. France-DMLA Study Group. Br J Ophthalmol. 1998;82(9):996-1002.
21. Fernandez AB, Wong TY, Klein R, et al. Age-related macular degeneration and incident cardiovascular disease: the Multi-Ethnic Study of Atherosclerosis. Ophthalmology. 2012;119(4):765-770.

22. Friedman $E$. The role of the atherosclerotic process in the pathogenesis of age-related macular degeneration. Am J Ophthalmol. 2000;130(5): 658-663.

23. Friedman E, Krupsky S, Lane AM, et al. Ocular blood flow velocity in age-related macular degeneration. Ophthalmology. 1995;102(4): 640-646.

24. Coffey M, Crowder GK, Cheek DJ. Reducing coronary artery disease by decreasing homocysteine levels. Crit Care Nurse. 2003;23(1): $25-30$.

25. Clarke R, Bennett DA, Parish S, et al; MTHFR Studies Collaborative Group. Homocysteine and coronary heart disease: meta-analysis of MTHFR case-control studies, avoiding publication bias. PLoS Med. 2012;9(2):e1001177.

26. Marinou K, Antoniades C, Tousoulis D, Pitsavos C, Goumas G, Stefanadis C. Homocysteine: a risk factor for coronary artery disease? Hellenic J Cardiol. 2005;46(1):59-67.

27. Gupta M, Sharma P, Garg G, Kaur K, Bedi GK, Vij A. Plasma homocysteine: an independent or an interactive risk factor for coronary artery disease. Clin Chim Acta. 2005;352(1-2):121-125.

28. Dzielińska Z, Kadziela J, Sitkiewicz D, et al. [Elevated levels of homocysteine in plasma as a risk factor for coronary artery disease]. Pol Arch Med Wewn. 2000;104(1):345-353.

29. Cleophas TJ, Hornstra N, van Hoogstraten B, van der Meulen J. Homocysteine, a risk factor for coronary artery disease or not? A metaanalysis. Am J Cardiol. 2000;86(9):1005-1009.

30. Meleady RA, Graham IM. Homocysteine as a risk factor for coronary artery disease. J Cardiovasc Risk. 1995;2(3):216-221.

31. Strålin P, Karlsson K, Johansson BO, Marklund SL. The interstitium of the human arterial wall contains very large amounts of extracellular superoxide dismutase. Arterioscler Thromb Vasc Biol. 1995;15(11): 2032-2036.

32. Axer-Siegel R, Bourla D, Ehrlich R, et al. Association of neovascular age-related macular degeneration and hyperhomocysteinemia. Am J Ophthalmol. 2004;137(1):84-89.

33. Coral K, Raman R, Rathi S, et al. Plasma homocysteine and total thiol content in patients with exudative age-related macular degeneration. Eye (Lond). 2006;20(2):203-207.

34. Kamburoglu G, Gumus K, Kadayifcilar S, Eldem B. Plasma homocysteine, vitamin B12 and folate levels in age-related macular degeneration. Graefes Arch Clin Exp Ophthalmol. 2006;244(5):565-569.

35. Dominguez LJ, Galioto A, Pineo A, et al. Age, homocysteine, and oxidative stress: relation to hypertension and type 2 diabetes mellitus. J Am Coll Nutr. 2010;29(1):1-6.

36. Strassburg A, Krems C, Lührmann PM, Hartmann B, NeuhäuserBerthold M. Effect of age on plasma homocysteine concentrations in young and elderly subjects considering serum vitamin concentrations and different lifestyle factors. Int J Vitam Nutr Res. 2004;74(2):129-136.

37. Ventura P, Panini R, Verlato C, Scarpetta G, Salvioli G. Hyperhomocysteinemia and related factors in 600 hospitalized elderly subjects. Metabolism. 2001;50(12):1466-1471.

38. Knowles RG, Moncada S. Nitric oxide synthases in mammals. Biochem J. 1994;298(Pt 2):249-258.

39. Menshikova EB, Zenkov NK, Reutov VP. Nitric oxide and NOsynthases in mammals in different functional states. Biochemistry (Mosc). 2000;65(4):409-426.

40. Alderton WK, Cooper CE, Knowles RG. Nitric oxide synthases: structure, function and inhibition. Biochem J. 2001;357(Pt 3):593-615.

41. Schmetterer L, Krejcy K, Kastner J, et al. The effect of systemic nitric oxide-synthase inhibition on ocular fundus pulsations in man. Exp Eye Res. 1997;64(3):305-312.

42. Luksch A, Polak K, Beier C, et al. Effects of systemic NO synthase inhibition on choroidal and optic nerve head blood flow in healthy subjects. Invest Ophthalmol Vis Sci. 2000;41(10):3080-3084. 
43. Deng LY, Thibault G, Schiffrin EL. Effect of hypertension induced by nitric oxide synthase inhibition on structure and function of resistance arteries in the rat. Clin Exp Hypertens. 1993;15(3):527-537.

44. Beckman JS, Beckman TW, Chen J, Marshall PA, Freeman BA. Apparent hydroxyl radical production by peroxynitrite: implications for endothelial injury from nitric oxide and superoxide. Proc Natl Acad Sci US A. 1990;87(4):1620-1624.

45. Blundell G, Jones BG, Rose FA, Tudball N. Homocysteine mediated endothelial cell toxicity and its amelioration. Atherosclerosis. 1996;122(2):163-172.

46. Totan Y, Cekiç O, Borazan M, Uz E, Sögüt S, Akyol O. Plasma malondialdehyde and nitric oxide levels in age related macular degeneration. Br J Ophthalmol. 2001;85(12):1426-1428.

47. Evereklioglu C, Er H, Doganay S, et al. Nitric oxide and lipid peroxidation are increased and associated with decreased antioxidant enzyme activities in patients with age-related macular degeneration. Doc Ophthalmol. 2003;106(2):129-136.
48. Lancaster JR Jr. Nitroxidative, nitrosative, and nitrative stress: kinetic predictions of reactive nitrogen species chemistry under biological conditions. Chem Res Toxicol. 2006;19(9):1160-1174.

49. Speyer CL, Neff TA, Warner RL, et al. Regulatory effects of iNOS on acute lung inflammatory responses in mice. Am J Pathol. 2003;163(6): 2319-2328.

50. Kar S, Kavdia M. Endothelial $\mathrm{NO}$ and $\mathrm{O}_{2}$ - Production rates differentially regulate oxidative, nitroxidative, and nitrosative stress in the microcirculation. Free Radic Biol Med. 2013;63:161-174.

51. Friedman E. A hemodynamic model of the pathogenesis of age-related macular degeneration. Am J Ophthalmol. 1997;124(5):677-682.

52. Vallance P, Leone A, Calver A, Collier J, Moncada S. Accumulation of an endogenous inhibitor of nitric oxide synthesis in chronic renal failure. Lancet. 1992;339(8793):572-575.
Clinical Ophthalmology

\section{Publish your work in this journal}

Clinical Ophthalmology is an international, peer-reviewed journal covering all subspecialties within ophthalmology. Key topics include: Optometry; Visual science; Pharmacology and drug therapy in eye diseases; Basic Sciences; Primary and Secondary eye care; Patient Safety and Quality of Care Improvements. This journal is indexed on

\section{Dovepress}

PubMed Central and CAS, and is the official journal of The Society of Clinical Ophthalmology (SCO). The manuscript management system is completely online and includes a very quick and fair peer-review system, which is all easy to use. Visit http://www.dovepress.com/ testimonials.php to read real quotes from published authors. 